\title{
Practices on Innovative Technologies: a digital (pre)fabrication experience at the undergraduate program in architecture and urbanism
}

XXIV International Conference of the Iberoamerican Society

of Digital Graphics

Medellin | Colombia

\author{
Sergio Kopinski Ekerman \\ Universidade Federal da Bahia | Brasil | sekerman@ufba.br
}

Larissa Gonçalves Maia da Silva

Universidade Federal da Bahia | Brasil | larissagmaias@gmail.com

\begin{abstract}
The present article describes an introductory digital (pre)fabrication course directed to undergraduate students in the School of Architecture at Universidade Federal da Bahia, its goals, processes and results, which aim at the update of technologies studies within the arrival of a customized CNC Router at the construction lab. "Practices on Innovative Technologies" brings the students into an experience of hands-on activities, both introducing digital fabrication technologies to their background as well as creating a critical and analytical understanding about these tools, using ferrocement prefabrication as a theoretical and practical framework.
\end{abstract}

Keywords: Digital Fabrication; CAD/CAM; Experimental Building Site; Prototyping; CNC; Prefabrication.

\section{INTRODUÇÃO}

A disciplina "Práticas em Tecnologias Inovadoras", voltada a estudos sobre novas tecnologias construtivas e industrialização da construção, pertence ao currículo optativo do curso de graduação em Arquitetura e Urbanismo da Faculdade de Arquitetura da Universidade Federal da Bahia (FAUFBA). Incorporada ao programa da graduação nos anos 1990 com o objetivo de estudar tecnologias construtivas inovadoras à época, tais como pré-vigas, pré-lajes, gesso acartonado, fachadas ventiladas, banheiros prontos, dentre outros, tornou-se gradualmente obsoleta, deixando afinal de ser oferecida. No ano de 2019, o curso foi retomado pelos autores do artigo, a partir da chegada de uma fresadora de Controle Numérico por Computador (CNC) de grande porte a FAUFBA, buscando investigar vantagens e limitações de tecnologias construtivas contemporâneas em arquitetura, urbanismo e construção.

A observação sobre processos de pré-fabricação apoiados pelo emprego da fresadora CNC é o mote principal do trabalho proposto, mais especificamente do campo da fabricação digital, utilizando a máquina para usinagem de fôrmas para peças leves de concreto ou argamassa armada. Além disso, a disciplina visa a fomentar, junto a outros componentes curriculares do curso, a formação do Canteiro Experimental da instituição, problematizando as tecnologias CAD (Computer Aided Design) e CAM (Computer Aided Manufacturing) frente à realidade local. Duas edições foram até então realizadas, nos semestres de 2019.1 e 2019.2 .

Este trabalho tem como objetivo apresentar a metodologia empregada ao longo do curso, registrando alguns dos resultados obtidos e, por fim, analisando as intenções, aprendizados e impactos deste componente curricular e do seu foco no tema da (pré) fabricação digital.

\section{METODOLOGIA}

O curso baseia-se na associação de sessões teóricas e práticas, sendo realizadas aulas expositivas e discussões de textos (Passaro \& Rhode, 2016; Fonseca de Campos et al., 2017; Fonseca de Campos, 2002; Coriat, 1983; Pupo \& Celani, 2008; Ratti, 2015; Frampton, 2010, dentre outros), os quais dialogam, em processo dinâmico, com sessões de desenvolvimento de projeto e prototipagem que empregam recursos analógicos e digitais, tanto no campo do desenho, quanto da construção.

Desta forma, de modo a auxiliar e embasar o processo projetual, o curso aborda conteúdos em duas vertentes complementares: pré-fabricação e fabricação digital.

Na primeira, são tratados aspectos da pré-fabricação em arquitetura a partir da obra do arquiteto João Filgueiras Lima, o Lelé, com foco no desenvolvimento tecnológico da argamassa armada, desde seu histórico na Europa, passando pela chegada ao Brasil através do Instituto de Arquitetura e Urbanismo da USP em São Carlos e consolidação em Salvador, chegando até aspectos construtivos e execução. Também são abordadas noções básicas de traço de concreto, construção e detalhamento de fôrmas para peças em concreto e argamassa armada, analisando de forma prática, por exemplo, o papel dos reforços metálicos difusos.

Já na segunda vertente, os estudantes são introduzidos ao Controle Numérico por Computador (CNC); ao estado da arte atual; à classificação dos métodos aditivos, subtrativos e formativos de fabricação digital (Pupo, 2008); ao conceito 
de G-Code e sua geração através de software específico; ao funcionamento e setup da máquina CNC e suas fresas; às definições para as estratégias de programação e operação da máquina; e aos processos de usinagem 2D e $3 \mathrm{D}$, com foco nos bidimensionais, a título do caráter introdutório proposto pela disciplina.

Para além das atividades executadas em sala de aula, as turmas, que têm número máximo de 15 alunos e contaram sempre com um monitor, realizaram visita técnica à planta de pré-fabricação industrial da Companhia de Desenvolvimento Urbano de Salvador (DESAL) - herdeira da Fábrica de Equipamentos Comunitários (FAEC), fábrica montada e coordenada por Lelé em Salvador entre 1985 e 1989 -, e que emprega argamassa armada em suas linhas de produção, sendo essa tecnologia pesquisada em bibliografia especializada (Hanai, 1992; Wainstock, 2010) ao longo do curso, em paralelo à capacitação no ferramental digital. A visita de campo consiste em um dos pontos altos do curso, momento em que o estudante visualiza o processo de produção de tradicionais equipamentos urbanos ainda hoje utilizados em Salvador, desenhados por Lelé e realizados através de fôrmas metálicas de grande complexidade.

É importante também pontuar que a comunicação entre o docente, os monitores e discentes foi estabelecida para além dos encontros presenciais, também com o emprego de ferramentas colaborativas virtuais. A comunicação e trabalho assíncrono entre professor e monitores foram realizados via plataforma "Trello" e, para comunicação com estudantes cursando a matéria, o ambiente virtual de aprendizagem utilizado pela UFBA (Moodle) serviu para acesso aos textos discutidos e entrega de produtos dos exercícios (fase de projeto).

\section{CURSOS DE REFERÊNCIA}

O curso teve, entre outras referências, a observação de atividades curriculares e pesquisas sobre fabricação digital realizadas em outras instituições, visitadas pelo Prof. Sergio Ekerman durante sua pesquisa de doutorado, entre 2014 e 2018, quais sejam: Universidade de Washington, em Seattle; Columbia University de Nova lorque; Graduate School of Design (GSD), Harvard University; e School of Architecture and Planning $(S A+P)$, Massachussets Institute of Technology, nos Estados Unidos, bem como a Faculdade de Arquitetura e Urbanismo da Universidade Federal do Rio de Janeiro (FAU-UFRJ) e Universidade Estadual de Campinas (Unicamp), no Brasil.

Atividades realizadas por professores como Kimo Griggs, Larry Sass, Martin Bechthold, Trevor Watson, Andrés Passaro e Gabriela Celani em suas respectivas instituições ajudaram a consolidar o pensamento em torno dos objetivos do curso. O componente curricular tem a finalidade de instigar o interesse pela fabricação digital, bem como de situar o estudante no âmbito da recomposição do trabalho no canteiro de obras de uma forma mais ampla neste início de século XXI (Deamer, 2010), sobretudo com relação ao contexto brasileiro. Em síntese, aproveitar o desenvolvimento de novas tecnologias para ampliar o papel da obra na instrução do arquiteto urbanista e, com isto, situá-lo em um referencial teórico engajado na realidade social vigente.

\section{ATIVIDADES E PRODUTOS}

Desenvolvido ao longo de um semestre (17 sessões semanais de $4 \mathrm{~h}$ de duração, $68 \mathrm{~h}$ totais), o trabalho consiste em projetar e construir um artefato pré-moldado em concreto ou argamassa armada, utilitário ou não, com dimensões de, aproximadamente, $50 \times 50 \times 50 \mathrm{~cm}$. Para tanto, os estudantes precisam associar o desenho das peças aos desafios particulares da concepção de sua fôrma, considerados o correto preenchimento e retirada dos objetos do molde, além de outras questões, conforme Mascarenhas (1988).

Tabela 1: Relação das atividades realizadas no curso, com número de sessões e seus objetivos. As sessões representam as aulas dedicadas a cada uma das atividades. A atividade "j" diferiu nas duas edições da disciplina realizadas em 2019 e, por esse motivo, tem dois formatos. Fonte: Acervo dos Autores.

\begin{tabular}{|c|c|c|}
\hline Atv. & Objetivo & Sessões \\
\hline a & $\begin{array}{l}\text { Aulas teóricas e discussões de texto para } \\
\text { embasamento dos desenhos e projetos }\end{array}$ & 3 \\
\hline$b$ & $\begin{array}{l}\text { Desenvolvimento de projeto por } \\
\text { desenhos e modelagem }\end{array}$ & 2 \\
\hline $\mathrm{c}$ & Apresentação e discussão dos projetos & 1 \\
\hline $\mathrm{d}$ & $\begin{array}{l}\text { Aula teórica e discussão de texto para } \\
\text { auxiliar desenvolvimento do protótipo }\end{array}$ & 1 \\
\hline $\mathrm{e}$ & Estudos e protótipo em escala a definir & 3 \\
\hline$f$ & Visita à DESAL & 1 \\
\hline g & Apresentação e discussão dos protótipos & 1 \\
\hline $\mathrm{h}$ & $\begin{array}{l}\text { Aula teórica e discussão de texto para } \\
\text { auxílio na execução da fôrma e objeto }\end{array}$ & 1 \\
\hline i & $\begin{array}{l}\text { Fabricação da fôrma e moldagem final do } \\
\text { artefato individual }\end{array}$ & 3 \\
\hline j & $\begin{array}{l}\text { Moldagem do objeto coletivo / Montagem } \\
\text { da exposição final }\end{array}$ & 1 \\
\hline
\end{tabular}

Nas primeiras etapas, o desenho analógico e a concepção do design do objeto por meio de croquis são estimulados, passando posteriormente aos softwares CAD 2D e 3D. De toda sorte, alguns trabalhos são concebidos desde 0 princípio em ferramentas digitais.

Pesquisas recentes no campo da fabricação digital com emprego de concreto indicam o uso único de fôrmas como uma limitação, vez que são perdidas na moldagem ou incorporadas aos objetos, devido às dificuldades de desmoldagem (Wangler, et al, 2016). Visando investigar possibilidades de reutilização da fôrma através de desenhos "open-source" (Ratti, 2015), é requisitado aos estudantes que dispensem o uso de pregos, parafusos ou colas, e que aproveitem a precisão do corte numérico para desenvolvimento de encaixes e articulações inteligentes e customizáveis, bem como passíveis de desenvolvimento compartilhado de código aberto. Em alguns exercícios foram utilizados, por exemplo, templates de corte do projeto WikiHouse (WikiHouse, n.d.). Neste sentido, os estudantes são estimulados a usar os recursos materiais com parcimônia, bem como a reutilizar peças usinadas na fase de prototipagem em concretagens subsequentes. 
Em seguida, os estudantes iniciam a prototipagem da fôrma em compensado naval com espessura de $17 \mathrm{~mm}$, a depender do tipo e das dimensões de cada objeto. Também é solicitado que os estudantes investiguem diferentes possibilidades para os encaixes ou aspectos específicos da fôrma (Figura 1), pensando, por exemplo, na mecânica e na resistência necessária ao processo de moldagem e desmoldagem, ou seja, desenvolvendo o projeto de forma mais ampla também a partir da solução de detalhes específicos.

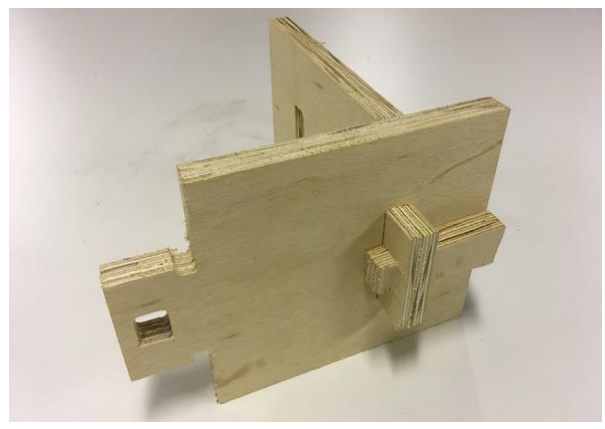

Figura 1: Imagem de protótipo de encaixes desmontáveis com emprego de cunha para teste de desempenho da solução. Fonte: Acervo dos Autores.

Após testes realizados com a fôrma, procede-se à moldagem e desmoldagem de peças de protótipo em uma etapa intermediária, o que se revelou como grande valia ao aprendizado (Figura 2). A seguir, desenvolve-se o projeto visando à fabricação definitiva da fôrma, confeccionada em compensado de madeira naval usinado na fresadora $\mathrm{CNC}$ e, por fim, as peças finais são moldadas, submetidas a cura e desmoldadas

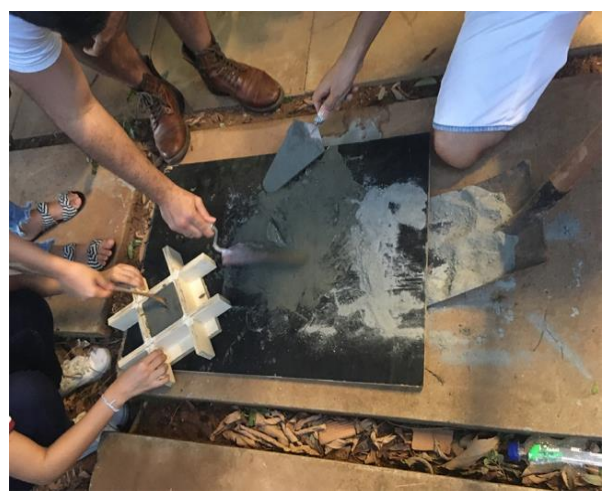

Figura 2: Mistura de argamassa feita pelos estudantes de 2019.1 com colheres de pedreiro para preenchimento da fôrma de um dos protótipos executados. A oportunidade da experiência manual permite aos alunos uma aproximação ao canteiro de obras. Fonte: Acervo dos Autores.

\section{EQUIPAMENTOS, MATERIAIS E SOFTWARES EMPREGADOS}

A realização das atividades descritas no tópico anterior (Tabela 1) apoia-se nas ferramentas e materiais disponibilizados para realização desses exercícios. À disposição dos estudantes para a etapa de desenho técnico e modelagem estão softwares CAD 2D e 3D como AutoCAD e Sketchup, com uso licenciado na FAUFBA. Ademais, os estudantes têm a possibilidade de utilizar a marcenaria da escola, que possui o ferramental necessário ao desenvolvimento dos exercícios.

Portanto, grande parte do trabalho de fabricação digital é realizado através de métodos subtrativos, com o emprego da fresadora CNC de grande formato, de produção nacional e customizada (Figura 3), com dimensões de $3 \times 2 \mathrm{~m}$.

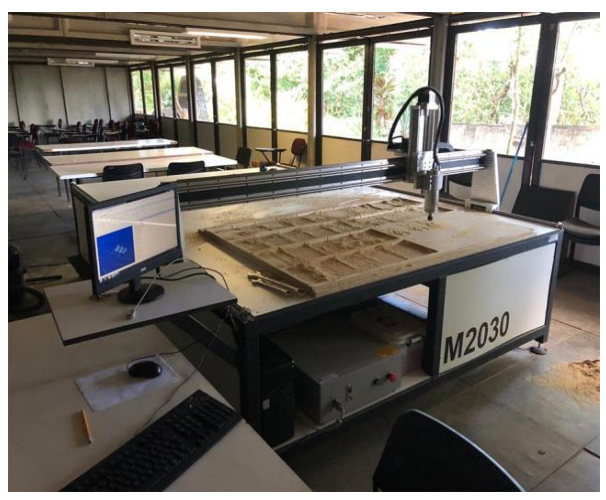

Figura 3: Fresadora de grandes dimensões $(3 \times 2 m)$ utilizada nas atividades do curso, no subsolo do Pavilhão lansã da FAUFBA. Máquina produzida pela empresa CNC Máquinas. Fonte: Acervo dos Autores.

Na usinagem, são utilizadas fresas de 1 e 2 fios de corte, de 4,0 e $6,0 \mathrm{~mm}$, para produzir peças de compensado naval de $17,0 \mathrm{~mm}$ de espessura, único material disponibilizado pela instituição de ensino e cuja escolha foi realizada por mera circunstância, em detrimento do uso, por exemplo, de fôrmas de compensado plastificado que seriam ideais para o exercício de moldagem de concreto e que, pela dimensão dos objetos, poderiam ser de menor espessura.

Tanto para a configuração das estratégias de corte e usinagem como para controle e operação da máquina, são empregados softwares fornecidos junto ao equipamento pelo fabricante CNC Máquinas. As estratégias de corte são definidas com o uso do programa ArtCAM, desenvolvido pela Delcam, empresa posteriormente adquirida pela Autodesk que, anos mais tarde, descontinuou o software (Autodesk, 2014; Autodesk Support, 2018). Para controle e operação da máquina, é utilizado o programa NCStudio, produzido pela Shanghai Weihong Technology Co. Os softwares são de fácil operacionalização, razão pela qual os alunos são estimulados a operá-los.

A experiência de "canteiro" é iniciada após os cortes controlados por computador e usualmente inclui a necessidade de seguir ao acabamento das fôrmas com o emprego de lixas (Figura 4). Em seguida, procede-se ao processo de manipulação da tela eletrosoldada - malha quadrada de $2,5 \mathrm{~cm}$ e fio 18 - para reforço do objeto (Figura 5) com uso de alicates e outros utensílios, bem como da produção manual da argamassa, desde a dosagem dos elementos para execução do traço, 
passando pela mistura manual com colher de pedreiro, como demonstrado anteriormente (Figura 2), chegando ao enchimento das fôrmas. Posteriormente, após a devida cura do material, as fôrmas são desmontadas para retirada dos objetos finalizados. Os alunos participam ativamente de todas as etapas.

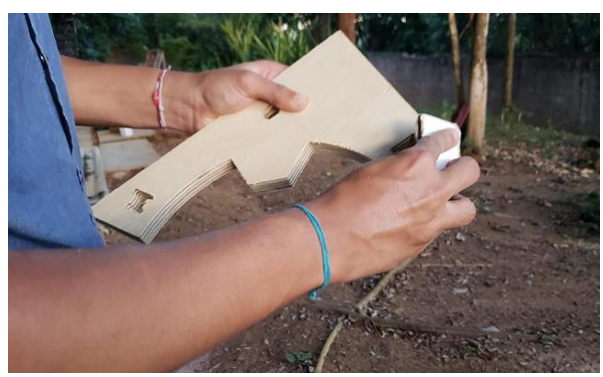

Figura 4: Estudante realiza acabamento com lixa em fôrma de compensado naval para assento de banco. Fonte: Acervo dos Autores.

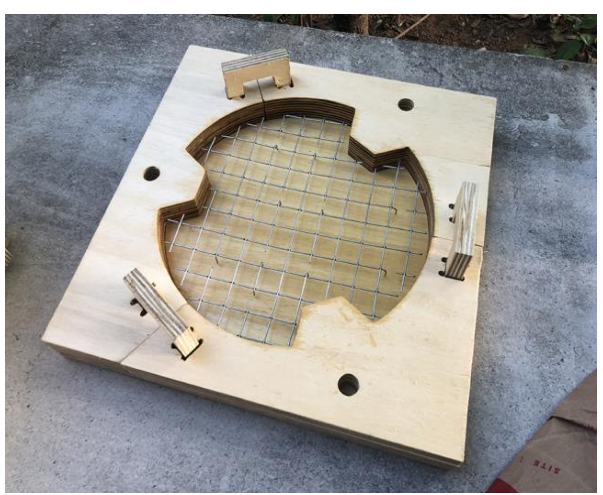

Figura 5: Tela eletrosoldada em fôrma montada para assento de banco em argamassa armada, do aluno Lucas Bomfim. Fonte: Acervo dos Autores.

A desforma emprega, em alguns casos, o uso planejado do martelo de borracha (Figura 6) ou outras ferramentas para auxílio do processo. A experiência dá aos alunos a oportunidade de melhor perceber o comportamento estrutural da argamassa armada e seu reforço após a cura do material, aprendendo com as dificuldades e limitações desse processo, também chamado desmoldagem.

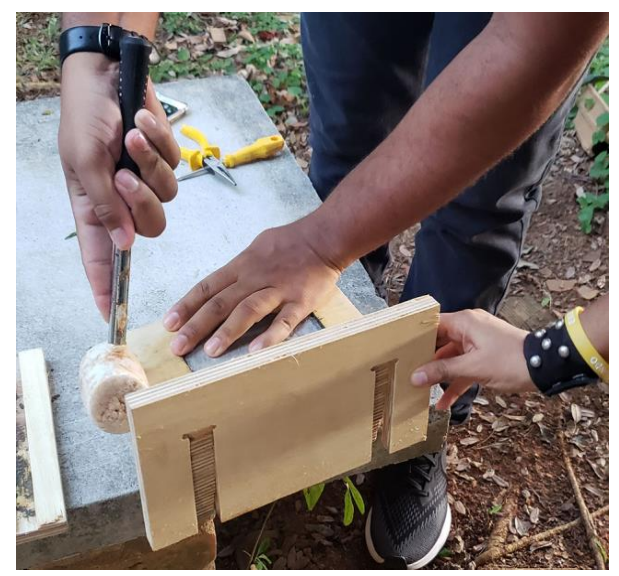

Figura 6: Uso do martelo de borracha na desmoldagem de um dos artefatos. Fonte: Acervo dos Autores.

\section{RESULTADOS \\ TIPOS DE FÔRMA E ENCAIXES}

Dada a natureza do trabalho solicitado aos estudantes, o desenho das fôrmas revela-se elemento central de investigação e ponto de síntese dos conhecimentos de fabricação digital e pré-fabricação incorporados ao curso, seja nas sessões teóricas, seja nas sessões práticas e na visita de campo.

Aspecto interessante a ser observado diz respeito ao fato de que, pelas características do material trabalhado e das técnicas disponíveis, as fôrmas projetadas usualmente não possuem o chamado arrasto, ou seja, a geometria oblíqua de suas paredes que facilita a retirada dos objetos do molde, como, por exemplo, no caso da fôrma de um bolo. Neste caso, diferentes estratégias foram desenvolvidas, não só para permitir a desmontagem da fôrma, mas também para lidar com as pressões da argamassa sobre o molde durante o processo de enchimento.

Surgiram, então, pelo menos três métodos de organização do compensado de madeira: a) em "camadas" superpostas (Figura 7); b) em planos contíguos; c) mais raramente, com paredes em perfil triangular, produzidas através de usinagem tridimensional da chapa de compensado (Figura 8), algo que também terá consequências no desenho da peça propriamente dita. Em alguns casos, os estudantes optaram por soluções híbridas (Figura 9), em fôrmas compostas por peças superpostas e planos "verticais" encaixados. 


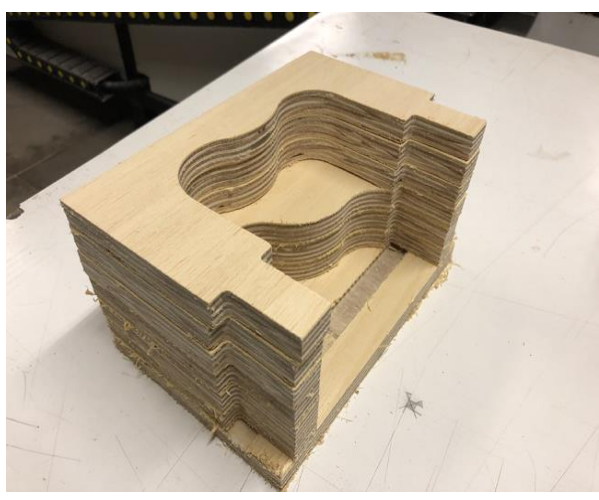

Figura 7: A superposição de "camadas" do compensado plano permite a moldagem de curvas e a adição de espessura nesses objetos. Artefato desenvolvido pelo estudante Rafael Teixeira. Fonte: Acervo dos Autores.

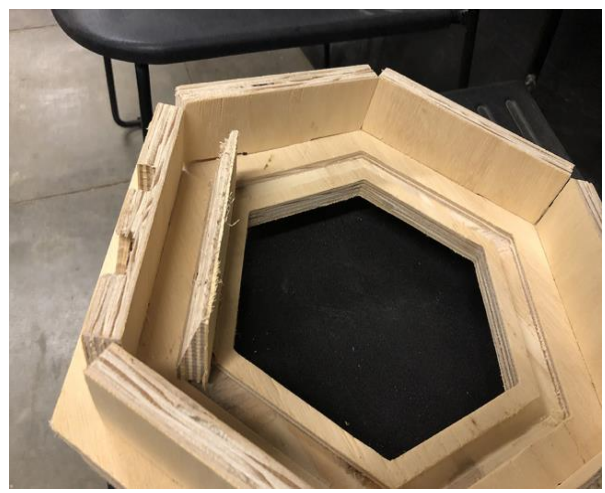

Figura 8: Fôrma de "cobograma" da aluna Isabele Lima com peça interna usinada de maneira tridimensional, permitindo assim o arrasto, além de interferir na geometria do objeto final. Fonte: Acervo dos Autores.

A adoção de peças auxiliares para fixação das fôrmas em prol da sua estabilidade durante a moldagem é também um dos problemas mais importantes colocados pelo exercício, gerando como resposta a criação de elementos de fixação e estabilização da fôrma sempre por encaixe e visando a possibilidade de montagem e desmontagem.

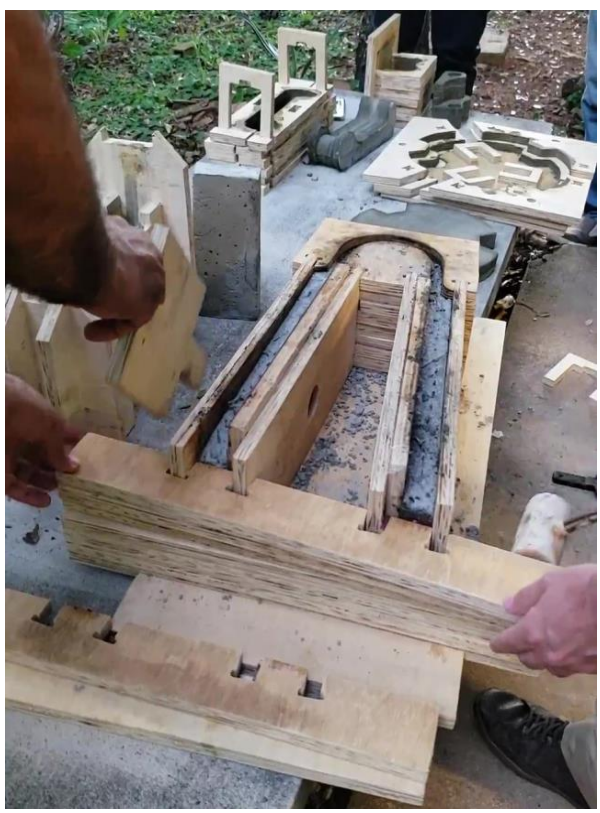

Figura 9: Em primeiro plano, bicicletário de autoria coletiva em argamassa armada sendo desmoldado. Pode-se notar mais de uma estratégia no projeto da fôrma, tanto camadas superpostas como planos contíguos, além de associação de camadas para alcançar variação de espessura. Ao fundo, outras fôrmas desenvolvidas na disciplina. Fonte: Acervo dos Autores.

Dentre as soluções desenhadas para manter a fôrma montada e estável durante o processo de confecção das peças destacam-se os encaixes fixados por cunhas, conforme o protótipo anteriormente mencionado (Figura 1), os grampos em forma de "U" (Figura 10) e encaixes tais como aqueles formados pela usinagem de "trilhos" em baixo relevo no compensado e cortes que permitem uma montagem entrelaçada das diferentes peças componentes da fôrma (Figura 11). Tais soluções exemplificam diferentes possibilidades e adaptações que surgem no decorrer da pesquisa realizada pelos estudantes e que aproveitam, no caso das peças superpostas, por exemplo, a capacidade da máquina de usinar curvas para apoio ao desenho dos objetos, bem como a precisão do corte para o jogo de interação entre os elementos da fôrma. 


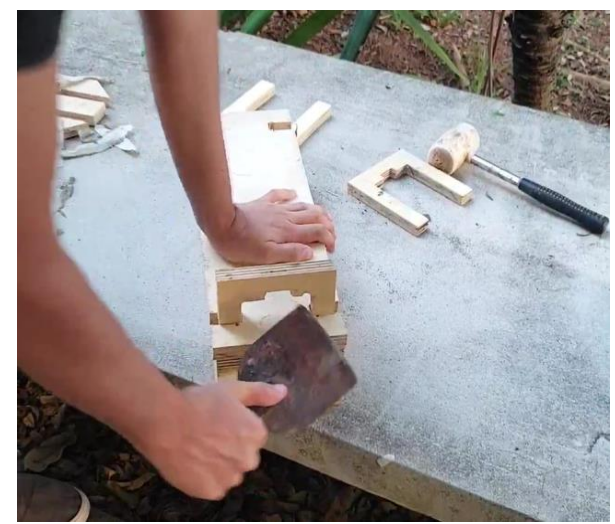

Figura 10: Exemplo de uso de grampos em U para fixação, onde um está sendo removido em primeiro plano, enquanto o outro se encontra em segundo plano, ao lado do martelo de borracha. Trabalho de Davi Bastos. Fonte: Acervo dos Autores.

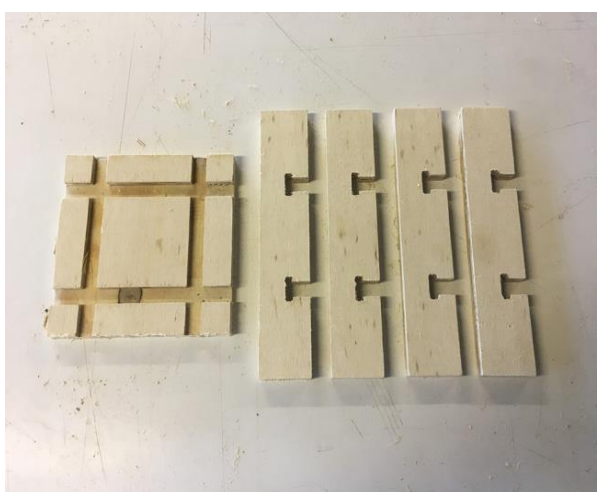

Figura 11: Imagem de protótipo com "trilhos" em baixo relevo na base e cortes que permitem entrelaçamento dos planos

contíguos das laterais da fôrma. Anteriormente, na Figura 2, foi mostrado este protótipo montado durante uma moldagem. Fonte: Acervo dos Autores.

\section{OBJETOS}

Em ambas as edições da disciplina, realizadas ao longo do ano de 2019, a última etapa consistiu na confecção de objetos desenvolvidos após as etapas de prototipagem e refinamento da fôrma (Figuras 12 e 13). Em 2019.1, os estudantes reuniram-se para o exercício final em dois grupos e executaram modelos distintos de uma peça para bicicletário, por decisão dos mesmos (Figura 14). Já em 2019.2, os alunos decidiram, com auxílio dos autores do artigo, realizar versões mais desenvolvidas dos objetos prototipados durante o curso, visando a montagem de uma exposição capaz de ampliar a visibilidade do trabalho realizado na oficina para o restante da comunidade acadêmica (Figura 15).
A primeira situação permitiu avançar para objetos de maior dimensão, enquanto a segunda alternativa resultou em um maior número de objetos de menor dimensão, realizados de forma individual, tais como bancos, porta-garrafas e vasos de planta (Figura 16). Conforme mencionado, em todos os casos é a própria construção da fôrma que define as características básicas do objeto, seja em função da moldagem, seja em função da desmoldagem.

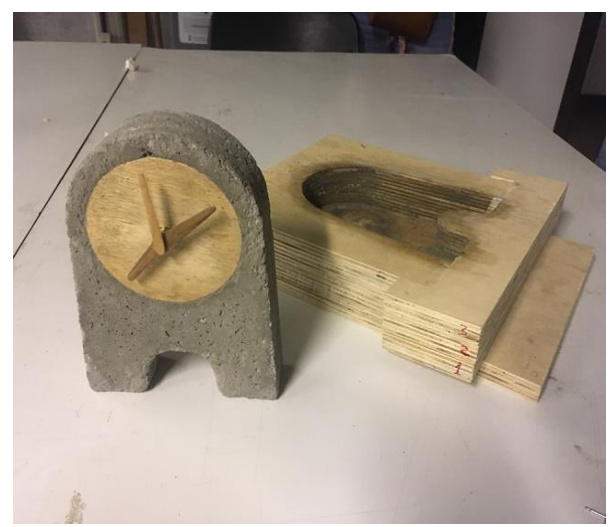

Figura 12: Relógio ao lado de sua fôrma, trabalho de Maria Clara Mattos, estudante da edição de 2019.1. Fonte: Acervo dos Autores.

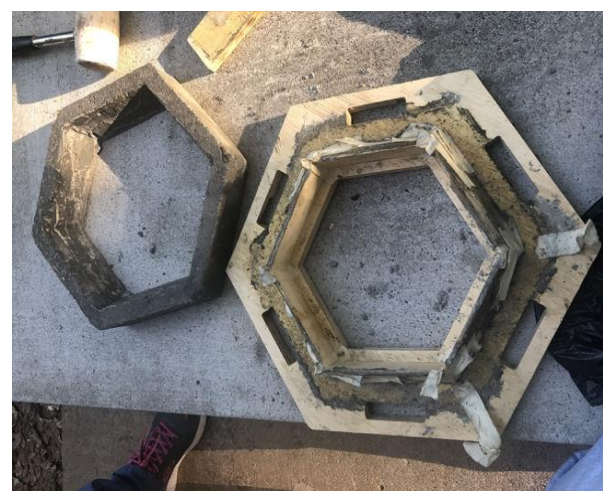

Figura 13: "Cobograma" e sua fôrma concebidos por Isabele Lima, estudante de 2019.2. Fonte: Acervo dos Autores. 


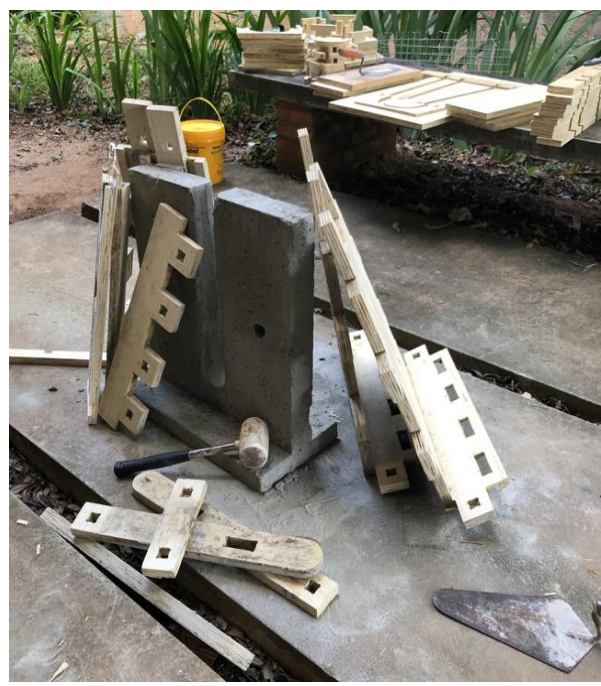

Figura 14: Um dos bicicletários de autoria coletiva, resultado de 2019.1, ao lado de peças de sua fôrma já desmontada e ferramentas. A fôrma empregou soluções anteriormente prototipadas e funcionou como síntese dos aprendizados nas experiências individuais. Fonte: Acervo dos Autores.

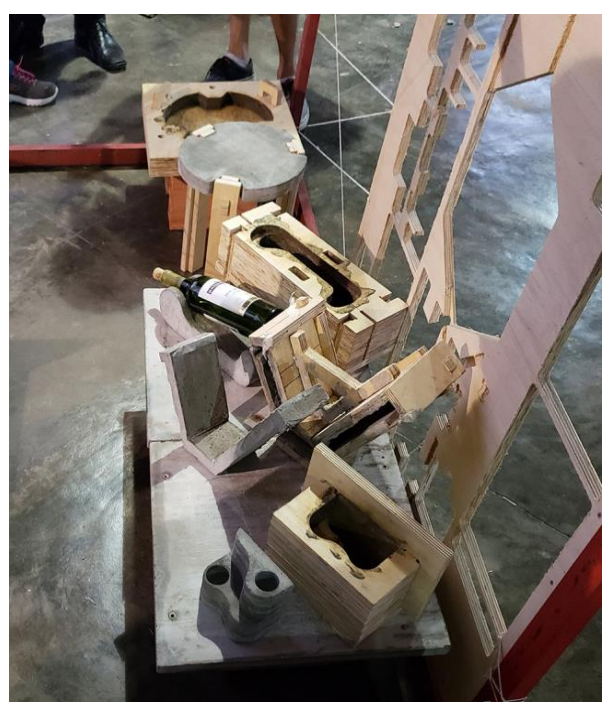

Figura 15: Exposição das fôrmas, objetos e placas resultantes dos cortes na fresadora CNC na edição de 2019.2. O objetivo foi unir a produção e expor resultados de pesquisa e trabalho realizados ao longo do período para o restante da comunidade acadêmica. São vistos na imagem os trabalhos dos estudantes Lucas Bomfim, Davi Bastos, Marcos Vinicius Pereira e Rafael Teixeira. Fonte: Acervo dos Autores.

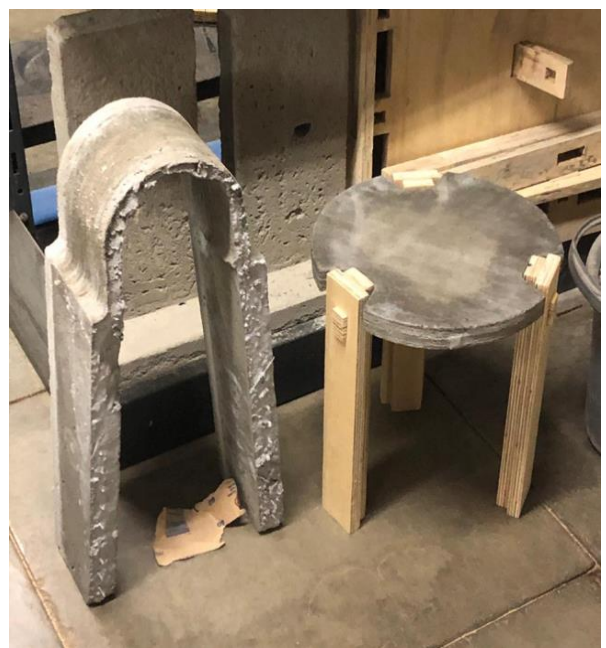

Figura 16: À esquerda da imagem, um dos bicicletários coletivos, resultado da edição de 2019.1, ao lado de banco desenvolvido pelo aluno Lucas Bonfim em 2019.2. É possível observar a diferença do volume de argamassa empregado em cada caso. Fonte: Acervo dos Autores.

\section{DISCUSSÃO}

A confluência das pesquisas em pré-fabricação e fabricação digital instigada pelo curso de graduação aqui descrito possui bom potencial para a instrução de estudantes de arquitetura e urbanismo, ajudando a consolidar uma formação ao mesmo tempo sólida, pelo contato com a construção, e atualizada pela oportunidade de utilização de tecnologias construtivas contemporâneas como mote central do trabalho, através do controle numérico por computador.

Além disso, apoiado em processos de construção coletiva do conhecimento, o curso apresenta um caráter de "condução" dos alunos ao longo dos trabalhos práticos, que, de acordo com Sawn et al., pode ser mais eficiente que um método de ensino por "instrução" (como citado em Eversmann, 2017, p. 3).

Compreender as vantagens da racionalização dos processos construtivos, no sentido do emprego de préfabricação e, através da obra de João Filgueiras Lima, junto às especificidades da relação entre repetição e customização trazida pela tecnologia $\mathrm{CNC}$ é outra característica do aprendizado alcançado.

Por outro lado, o curso precisa ainda avançar na capacidade de incorporar de forma mais natural elementos de usinagem tridimensional, algo também influenciado pelo tempo disponível para o uso da máquina e a infraestrutura do laboratório para funcionamento contínuo, algo ainda em desenvolvimento na FAUFBA. Adicionalmente, a utilização de fôrmas de compensado plastificado em substituição ao compensado naval parece ser um passo importante para seguir aprimorando os resultados obtidos. 


\section{CONSIDERAÇÕES FINAIS}

Caminhando na fronteira entre ensino e pesquisa, o curso do componente optativo "Práticas em Tecnologias Inovadoras", da Faculdade de Arquitetura da UFBA, procura encontrar boa sintonia entre tecnologia, construção, arquitetura e urbanismo. A exploração das capacidades da fresadora CNC desdobra-se numa atualização das discussões tradicionais acerca da préfabricação, incorporando aspectos contemporâneos do universo da fabricação digital. De forma lúdica e a partir de exercício prático, pretende-se, assim, desenvolver com o profissional em formação uma visão madura, crítica e reflexiva sobre métodos CAM na atualidade, situando na realidade nacional os impactos do desenvolvimento tecnológico sobre nossa sociedade e ampliando sua visão sobre os aspectos práticos do ofício.

\section{AGRADECIMENTOS}

Agradecemos à Diretoria da Faculdade de Arquitetura da UFBA por seu apoio na viabilização da infraestrutura necessária à realização das atividades, na pessoa da exDiretora, a Professora Naia Alban Suarez. Agradecemos também ao então estudante Max Klug, monitor da disciplina no semestre 2019.1.

\section{REFERÊNCIAS}

Autodesk. (2014, Feb 06). Autodesk Completes Acquisition of Delcam. Retrieved from https://investors.autodesk.com/newsreleases/news-release-details/autodesk-completesacquisition-delcam.

Autodesk Support. (2018, Jul 18) Download old legacy Delcam products and updates. Retrieved from https://knowledge.autodesk.com/support/featurecam/troubles hooting/caas/sfdcarticles/sfdcarticles/Download-old-legacyDelcam-products-and-updates.html.

Coriat, B. (1983). O Processo de Trabalho de Tipo "Canteiro" e sua Racionalização: observações sobre algumas tendências da pesquisa atual. "O Trabalho em Canteiros" Plano Construção e Habitat. Paris, França: Université Paris VII.

Deamer, P. \& Bernstein, P. (Ed.). (2010). Building (in) the future: recasting labor in architecture. New Haven, Connecticut: Yale School of Architecture.
Fonseca de Campos, P. E. (2002). Da argamassa armada ao microconcreto de alto desempenho: perspectivas de desenvolvimento para a pré-fabricação leve (Tese de Doutorado), Universidade de São Paulo, São Paulo, Brasil.

Fonseca de Campos, P. E., Lopes, E. I., Yamana, D. N., \& Medeiros, J. (2017). Calçadas Drenantes: Intervenções físicas com desenvolvimento social. SIGraDi 2017, XXI Congreso de la Sociedad Ibero-americana de Gráfica Digital. SIGraDi, Concepción, Chile.

Eversmann, P. (2017). Digital Fabrication in Education: Strategies and Concepts for Large-Scale Projects. In Fioravanti, A., Cursi, S., Elahmar, S., Gargaro, S., Loffreda, G. Novembri, G. \& Trento, A. (Eds.), ShoCK! - Sharing of Computable Knowledge - Proceedings of the 35th International Conference on Education and Research in Computer Aided Architectural Design in Europe. Roma, Itália: Sapienza University of Rome.

Frampton, K. (2010). Intention, Craft, and Rationality. In: Deamer, P. \& Bernstein, P. (Eds.) Building (in) the future: recasting labor in architecture. (pp. 28-37) New York: Princeton Architectural Press.

Hanai, J. B. de. (1992). Construções de Argamassa Armada: fundamentos tecnológicos para projeto e execução. São Paulo, Brasil: Pini.

Mascarenhas, A. C. (1988). Fôrmas para concreto. Salvador, BA: Centro Editorial Didático da Universidade Federal da Bahia.

Passaro, A., \& Rohde, C. (2016, Jul-Set). Casa Revista: arquitetura de fonte aberta. Gestão e Tecnologia de Projetos, 11(2), 25-41.

Pupo, R. T. \& Celani, G. (2008). Prototipagem rápida e fabricação digital para arquitetura e construção: definições e estado da arte no Brasil. Parc Fec.Unicamp, v. 31, (3), 1-19.

Ratti, C. \& Claudel, M. (2015). Open-source architecture. London: Thames and Hudson.

Wainstock, H. (2010). Ferrocemento: diseño y construcción. 4ta. ed. Riobamba, Ecuador: Red Ecosur.

Wangler, T., Lloret, E., Reiter, L., Hack, N., Gramazio, F., Kohler, M., Bernhard, M., Dillenburger, B., Buchli, J., Roussel, N. \& Flatt, R. (2016). Digital Concrete: Opportunities and Challenges. RILEM Technical Letters, 1, pp. 67-75. doi: 10.21809/rilemtechlett.2016.16.

WikiHouse. (n.d.). Retrieved from https://www.wikihouse.cc/ 